\title{
Enfermedades que afectan a las plantas de hibiscus cultivadas como ornamentales en Corrientes
}

\author{
${ }^{1}$ Cabrera, María G.; ${ }^{1}$ Álvarez, Roberto E; ${ }^{1}$ Gutiérrez, Susana A.; \\ ${ }^{1}$ Cúndom, María A; ${ }^{2}$ Sosa López, Angela A. \\ ${ }^{1}$ Cátedra de Fitopatología, ${ }^{2}$ Cátedra de Química Orgánica y Biológica. Facultad de Ciencias Agrarias. \\ Universidad Nacional de Nordeste. Sargento Cabral 2131, (3400) Corrientes, Argentina.
}

\begin{abstract}
Resumen
En la provincia de Corrientes se observó que muchos ejemplares de Hibiscus cultivados como ornamentales, presentaban enfermedades que afectaban su estética y debilitaban las plantas. Se recolectaron para su estudio muestras de Sinencia o Rosa de la China (Hibiscus rosa-sinensis L.), rosa de Jamaica o de Abisinia (Hibiscus sabdariffa L.), rosa de Siria (Hibiscus syriacus L.) y ejemplares de Abutilon x hybridum hort., con el objeto de reconocer que patógenos afectaban a estas especies de Malvaceae en la provincia de Corrientes y caracterizar las enfermedades que provocaban. En algunos casos los síntomas afectaban a las hojas y en otros a toda la parte aérea de las plantas con manifiestas alteraciones. El objetivo del presente trabajo fue identificar al agente causal de cada enfermedad de las especies ornamentales de los géneros Hibiscus y Abutilon presentes en viveros, plazas y paseos ubicados en varias localidades de la provincia de la Corrientes. Se siguieron las técnicas usuales de laboratorio para el estudio de estas enfermedades y sus agentes causales y revisión de bibliografía. Se determinaron: el agente causal de antracnosis, Colletotrichum gloeosporioides; el causante de la cercosporiosis Cercospora hibisci; una roya causada por una cepa de Cerospsora sp. y también se observaron sintomatologías similares a virus como las causadas por Hibiscus chlorotic ringspot carmovirus (HCRSV) y Abutilon mosaic virus Morren (AMV) sobre H. rosa-sinensis y H. syriacus. Palabras clave: ornamentales, patologías, patógenos.
\end{abstract}

\begin{abstract}
Summary
Several specimens of Hibiscus cultivated as ornamental with diseases symptoms were observed in the Corrientes province. These diseases affecting the esthetical presentation and weaken plants. Samples of Hibiscus rosa-sinensis L., Hibiscus sabdariffa and Hibiscus syriacus L. plants were collected for to study with the aim to know the pathogens that affecting these plants species in Corrientes and to characterize the diseases. Any cases the symptoms are only foliar but in other the complete canopy manifest pathologic disturbance with severity often important. Traditional method and techniques of laboratory, measuring and bibliography were used by to determine to Colletotrichum gloeosporioides pathogens affecting to $H$. rosa-sinensis and $H$. syriacus. Cercospora hibisci to $H$. rosa-sinensis, a rust on H. syriacus, and virosis similarly to Hibiscus chlorotic ringspot carmovirus (HCRSV) and Abutilon mosaic virus Morren (AMV) on H. rosa-sinensis and H. syriacus
\end{abstract}

Key words: ornamentals, pathology, pathogens.

\section{INTRODUCCIÓN}

Entre los años 2006 y 2011 se recolectaron materiales para identificación de los agentes causales de enfermedades de especies ornamentales en viveros, plazas y paseos ubicados en varias localidades de la provincia de la Corrientes. Entre los materiales recolectados se trabajó con ejemplares de Hibiscus rosa-sinensis L. (sinencia o Rosa de la China), Hibiscus sabdariffa L. (rosa de Jamaica o de Abisinia), e Hibiscus syriacus L. (rosa de Siria.), también ejemplares de Abutilon x hybridum hort., todos pertenecientes a la familia de las Malvaceae, con síntomas diversos, variables en magnitud según la época del año en que se observaron.
La Fam. Malvaceae cuenta con abundantes especies silvestres y varias cultivadas, entre ellas el género Hibiscus con cerca de 300 especies y formas especiales, desde herbáceas a arbustos leñosos y árboles (Planeta-De Agostini 1987; Murdoch Books 2008). Entre las especies cultivadas en la región la más abundante es $H$. rosa-sinensis, una planta arbustiva o árbol de poca altura, probablemente originaria de regiones tropicales de Asia, que se usa como ornamental por su abundante y prolongada floración y verdor permanente. Ésta, presenta cultivares de flores rojas, rosadas, amarillas, blancas o anaranjadas, en variantes de pétalos simples y dobles. También se encuentran variedades en el color del follaje (Daughtrey 
et al. 1995). Los ejemplares jóvenes de H. rosa-sinensis observados en predios particulares y paseos de la ciudad de Corrientes, manifestaban síntomas consistentes en manchas pequeñas de color castaño a negro, más o menos circulares, dispersas por la superficie de las hojas bien desarrolladas, también clorosis, manchado foliar, deformaciones de órganos y defoliación abundante.

En los ejemplares de rosa de Siria se observaron áreas necróticas, irregulares a redondeadas y extensas, distribuidas aleatoriamente o próximas a los márgenes foliares. Estos síntomas característicos de las llamadas comúnmente "antracnosis" disminuyen la calidad de ornato de diversas especies de acuerdo a Chase (1987) y Fernández Valiela (1979). Como antecedentes sobre enfermedades y patógenos que afectan a Rosa China y Rosa de Siria se encontraron trabajos de Daughtrey et al. (1995), Chase (1987) y en el Agriculture Handbook № 165, 1960. Estos autores mencionan varios hongos, bacterias y virus como agentes patógenos de las Malvaceae y en forma particular sobre especies del género Hibiscus. En la bibliografía nacional consultada las informaciones sobre enfermedades en estos hospedantes son comunicaciones breves como las de Sosa de Castro et al. 2002; Cabrera y Gutiérrez 2003. Se propuso el estudio de dichas enfermedades a fin de caracterizarlas y ofrecer una herramienta para su control, dado la importancia de dichas especies como ornamentales en la provincia de Corrientes.

\section{MATERIALES Y MÉTODOS}

Para obtener material de estudio se visitaron periódicamente los principales centros de producción $\mathrm{y}$ venta de plantas ornamentales (invernaderos y florerías), de la ciudad de Corrientes (depto. Capital), Santa Rosa (depto. Concepción), Santa Ana (depto. San Cosme) y Virasoro (depto. Santo Tomé) en la provincia de Corrientes. Se recolectaron muestras de plantas enfermas de $H$. rosa-sinenis L. (sinencias), $H$. sabdariffa L. e H. syriacus L., además de ejemplares de Abutilon x hybridum hort. (Malvaceae),

Las muestras recolectadas se agruparon por "tipo de síntoma”. Para mayor precisión sobre estos síntomas y signos externos se realizaron exámenes macroscópicos y con microscopio estereoscópico. Se examinó el tipo, forma, tamaño y color de lesiones presentes en las hojas enfermas y la presencia de signos. También se hicieron exámenes microscópicos (microscopio óptico 450x) para observar la presencia de organismos que pudieran ser patogénicos respecto al síntoma observado.

Distintos órganos de las plantas enfermas se colocaron en cámaras húmedas saturadas para favorecer la esporulación (en caso de que fueran hongos) en el material en estudio.
Fracciones de $1-2 \mathrm{~mm}^{2}$ de tejidos vegetales afectados, esterilizados con hipoclorito de sodio al 2,5\%, se sembraron en placas de Petri con agar papa glucosado (APG), al 1,5\%, $\mathrm{pH}=7$, luego se incubaron en estufa a $25-27^{\circ} \mathrm{C}$.

Para cumplir con los postulados de Koch se inocularon plantas sanas con los aislados obtenidos en cultivo puro de los diferentes organismos que desarrollaron en las placas con agar. Se cortaron discos de $0,5 \mathrm{~cm}^{2}$, conteniendo micelios y/o esporas desarrolladas en dicho medio agarizado, de 7 días de desarro1lo. Este inóculo se sostuvo sobre el órgano vegetal a inocular mediante un apósito de algodón embebido en agua estéril y cinta adhesiva transparente. Las plantas se embolsaron durante 72 horas posteriores a la inoculación. Pasado dicho lapso se retiraron las bolsas. Los testigos correspondientes se inocularon solo con APG.

Para determinar la etiología se realizaron observaciones de distintos preparados de las partes vegetativas y reproductivas de los organismos aislados en agua observando en microscopio 450X. Se procedió de esta forma también con el material de los aislamientos, de cortes histológicos y de raspado de las manchas o lesiones del material fresco (hojas, flores, raíces o tallos enfermos). Se determinaron datos morfométricos de las estructuras de cada organismo asociado a los tejidos enfermos de las plantas.

Se complementó con dibujos en cámara clara de las diversas estructuras fúngicas observadas.

En la identificación de los microorganismos patógenos se hizo el seguimiento de las plantas inoculadas para observar si los síntomas eran idénticos a los observados en el material colectado.

\section{RESULTADOS Y DISCUSIÓN}

Según los organismos que desarrollaron se consultó bibliografía especializda como Hawksworth et al. (1995), Albuy y Devergne (2000), Arx (1970), Barnett y Hunter (1972), Braun y Melnik (1997), Ellis (1971, 1976), Fernández Valiela (1979), Lindquist (1982), Sutton (1980).

\section{ANTRACNOSIS}

En infecciones naturales, tanto $H$. rosa-sinensis como $H$. syriacus presentaron infecciones necróticas con síntomas de manchas castaño grisáceas o a veces de color negro, irregulares y extensivas a casi circulares con un halo muy marcado, aisladas y dispersas por todo el limbo, que se inician como puntos oscuros rodeados de un fino halo amarillento (Fig. 1A).

Al evolucionar la infección, el centro de las lesiones se aclara, delimitándose por márgenes de color castaño oscuro, rodeados de halo clorótico. En el centro de las lesiones se observan puntuaciones negras, ligeramente elevadas, constituidas por acérvulos 


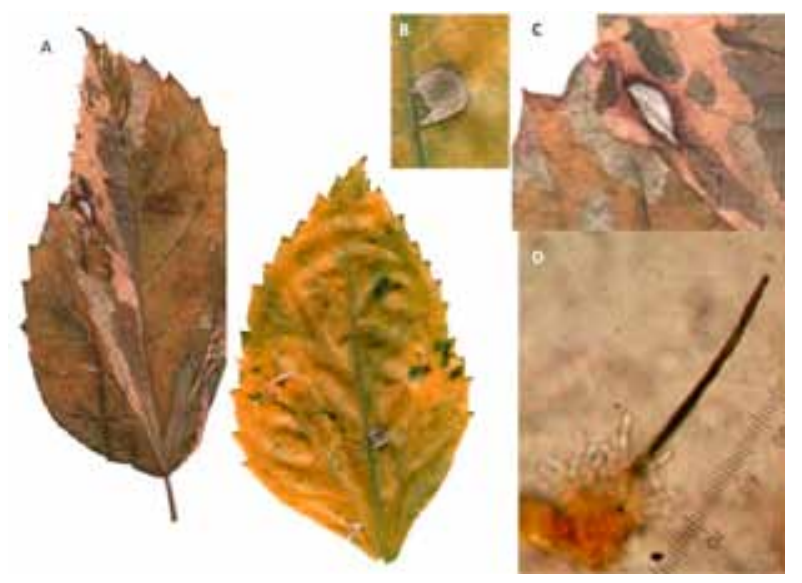

Fig. 1. A y B: Síntomas necróticos en hojas de Hibiscus rosa-sinensis de material infectado naturalmente; C: síntomas en hojas inoculadas. D. Conidióforos, conidios y seta de C. gloeosporioides en Hibiscus sp.

subepidérmicos (Fig. 1B, C). Las numerosas lesiones que infectan las hojas determinan que pronto se tornen cloróticas y se produzca su abscisión temprana.

Estos síntomas se observaron afectando hojas a distintos niveles en los arbustos de más de un año y también se determinó su presencia en plantas nuevas en macetas. La importancia de la enfermedad radica en la defoliación que provoca pérdidas de calidad en las plantas las cuales muestran ramas casi desnudas. La presencia de acérvulos confirmó que es una enfermedad de origen fungoso del tipo antracnosis. Esta es una patología que se registra en un elevado porcentaje de ejemplares de ambas especies de Hibiscus en Corrientes.

En la prueba de patogenicidad (positiva) los signos del patógeno se observaron solo cuando las lesiones evolucionaron hacia la necrosis completa del tejido infectado y en el centro se reprodujeron los acérvulos típicos, de hasta $200 \mu \mathrm{m}$ de diámetro. Estas son estructuras errumpentes, de las cuales se proyectan numerosas setas oscuras, casi negras, que miden en promedio $25 \mu \mathrm{m}$. Los acérvulos están constituidos por abundantes conidióforos, hialinos, fialiformes y muy cortos (Fig. 1D). Los conidios son unicelulares, hialinos, rectos, cilíndricos, de extremos redondeados, gutulados, con una medida promedio de 5,8×2,5 $\mu \mathrm{m}$, pudiendo observarse algunos conidios cilíndricos de hasta $25 \mu \mathrm{m}$. El conjunto de esporas maduras sobre los acérvulos forman un cirro cremoso, de color rosado-amarillento. Estas características se correspondieron con las del género Colletotrichum Corda, con teleomorfo en el género Glomerella Spauld \& Schhrenk, de acuerdo con Hawksworth et al. (1995). Estos hongos son causantes de manchas denominadas antracnosis y fueron también observados por Sosa de Castro et al. (2002). Si bien las manchas de antracnosis son generalmente irregulares y extensivas en coincidencia con lo acotado por Agrios (2005) y Fernández Valiela (1979), los síntomas pueden variar en una gama muy amplia, según la relación hospedantepatógeno que se trate. En el Agriculture Handbook No 165 1960, se menciona a Colletotrichum hibisci Pollaci como agente de la enfermedad en Malvaceae, pero se carecen de datos para confrontar con los resultados de este estudio.

Asimismo, en algunos ejemplares de rosa de Siria (H. syriacus) en correspondencia a los síntomas de clorosis se detectaron en el envés foliar, ampollas de coloración oscura, a modo de estructuras pequeñas y numerosas, conformando agrupaciones concéntricas. Con ayuda de la lupa se observó que estos síntomas y signos de enfermedad, estaban constituidos por masas de esporas claras y setas oscuras del hongo causante de la enfermedad. Igual que en la Rosa China, en la Rosa de Siria los conidios son unicelulares, hialinos, rectos, cilíndricos, de extremos redondeados, gutulados, con una medida promedio de $6-15 \times 2,7-4$ $\mu \mathrm{m}$, pudiendo observarse algunos conidios mucho más largos. En este caso el conjunto de esporas de las acérvulas ofrece un aspecto cremoso de color blanco sucio a amarillento. En estos soros se observó también la presencia de numerosas setas oscuras, casi negras, que miden entre 22-29 $\mu \mathrm{m}$ de longitud (Fig. 1D).

Tanto el agente causal de la antracnosis en Rosa China como el de Rosa de Siria producen acérvulos con abundantes conidióforos fasciculados, unicelulares, hialinos. Puestos a germinar los conidios emitieron tubos de germinación hialinos, de longitud variable y apresorios oscuros, globosos a irregulares. En ambos casos en los cultivos desarrollaron colonias circulares, inicialmente blancas con aspecto aterciopelado y posteriormente de coloración gris oliváceo con el centro más oscuro y blanco en el contorno. Sobre el micelio se formaron conjuntos de esporas llamados cirros de aspecto gelatinoso de color blanco amarillento que se oscurecen con la edad. En las colonias de 10 días de crecimiento, en el centro de las mismas y dispuestos en círculos concéntricos se observaron acérvulos de estromas más oscuros, con setas y esporulación abundante. El sustrato no fue teñido por el hongo. Asimismo, en colonias viejas (de más de 20 días), se observaron formaciones oscuras de células esclerotinosas en distintos puntos y sobre las paredes laterales de las placas de Petri. Estas características fueron coincidentes con las descriptas por Sutton (1980) para Colletotrichum gloeosporioides (Penz) Sacc., aunque este autor no menciona a Hibiscus como hospedante ni tampoco lo menciona Fernández Valiela (1979). El hongo es polífago y sus cepas afectan a un amplio rango de hospedantes de acuerdo con Dawghtrey et al. (1995). Por otro lado von Arx (1970) describió colonias de C. gloeosporioides como muy variables en medios de cultivo, en tan- 
to Sutton (1980), las describe con caracteres morfológicos similares a las estudiadas en este trabajo, pero de dimensiones ligeramente mayores a las registradas en rosa china y rosa de Siria. Este autor agrega que $C$. gloeosporioides presenta ocasionalmente esclerocios, característica manifestada en nuestros aislamientos por las estructuras esclerotinosas observadas en las placas de Petri. Estos aislamientos se identificaron como pertenecientes al hongo anamorfo C. gloeosporioides (Penz.) Sacc., del Orden Melanconiales, en acuerdo a lo informado por Álvarez y Cabrera (2008). Es probable que la diferencia observada en las cepas de Colletotrichum sobre ambas especies de Hibiscus puedan expresarse como correspondientes a diferentes especies, pero hasta el momento se carecen de elementos de referencia para su definición como tales.

\section{VIRUELA}

Algunas muestras de rosa china procedentes de la ciudad de Virasoro mostraron lesiones redondeadas de 0,3 - 0,6 cm de diámetro con márgenes de coloración pardo-rojiza, asociados a un hongo cercosporoide según las informaciones de Barnett \& Hunter (1980) y Ellis $(1971,1976)$, pero cuyas características morfo-anatómicas se ajustaron más a lo informado por Braun y Melnik (1997) sobre Cercospora hibisci Tracy \& Earle.

\section{ROYA}

En ejemplares de rosa de Siria $(H$. syriacus) en correspondencia a síntomas de clorosis, se detectaron soros pequeños y abundantes con características de roya en el envés foliar. Los órganos afectados por la enfermedad se reducían a las hojas. Los síntomas observados constituían áreas cloróticas, redondeadas, puntiformes, muy abundantes, distribuidas alrededor o próximas a las nervaduras principales de la cara superior de las hojas. En el envés foliar se formaban numerosas pústulas redondeadas, pequeñas y de coloración beige, conformando agrupaciones concéntricas (Fig. 2A).

Con ayuda de una lupa se observó que el polvillo de color claro estaba constituido por las masas de esporas (uredosporas) del hongo causante de la enfermedad. Con métodos de rutina en la identificación de patógenos obligados de plantas se determinó la presencia de una roya, cuyo agente pertenece al filum Basidiomycota del orden Uredinales (Agrios 2005), cuyo nombre se da tanto a la enfermedad como a los hongos que las producen. Estos son hongos biotróficos con ciclo de vida complejo. Sus agentes son organismos bastante específicos y su gama de hospedantes es relativamente reducida y específica (Fernández Valiela 1979). La roya que afecta a $H$. syriacus $\mathrm{L}$. en Corrientes es diferente a las royas comunes, pues su esporulación es muy pálida con semejanza a arenilla sobre los órganos enfermos. El diámetro de las áreas de infección oscilaba alrededor de 3-5 mm. Como signo se observaron pústulas subepidérmicas, casi incoloras al principio que se tornan de coloración beige a la madurez, redondeadas, y a veces más o menos alargadas; estas pústulas se encontraron aisladas, o en agrupaciones circulares, a veces confluentes formando soros alargados e irregulares (Fig. 2B). Con el avance de la enfermedad, las zonas cloróticas se transformaron en tejido necrótico (en la cara superior de la hoja), mientras en la inferior se observaron las pústulas, de color beige pálido, tornándose pardo-amarillento a medida que envejecieron. Las uredosporas son globosas, ovoides, de episporio espinulescente, de color beige amarillento muy pálido de $18,7-25(-21,8) \times 9,5-17,5(-22,5) \mu \mathrm{m}$. (Fig. 2C). Posee tres poros germinativos equidistantes. Alrededor de los soros se observan numerosas paráfisis en forma de sacos o clavas irregulares, hialinas, adelgazadas hacia la base, de $30 \mu \mathrm{m}$ de longitud promedio. Las teleutosporas, en soros más oscuros que no se abren, son incoloras, unicelulares, sobre un corto apéndice a modo de pie. No parecen terminar su ciclo por la invasión de hiperpárásitos abundantes que sufre el patógeno.

En Argentina Fernández Valiela (1979) y (Lindquist 1982), informaron a Puccinia malvacearum, Puccinia schedonnardi, y especies de Kuehneola y Phragmidium sobre miembros de la familia Malvaceae. Ahora, si comparamos a Puccinia schedonnardi Kell. \& Swing sobre Hibiscus, de "uredosoros epífilos, alargados, morenos, esparcidos, uredosporas globosas o anchamente elipsoidales, membranas morenas, con 6-8 poros germinativos esparcidos", no se ajusta al patógeno estudiado en $H$. syriacus. El mismo autor informa a Puccinia malvacearum Mont. como especie que afecta a por lo menos 40 especies

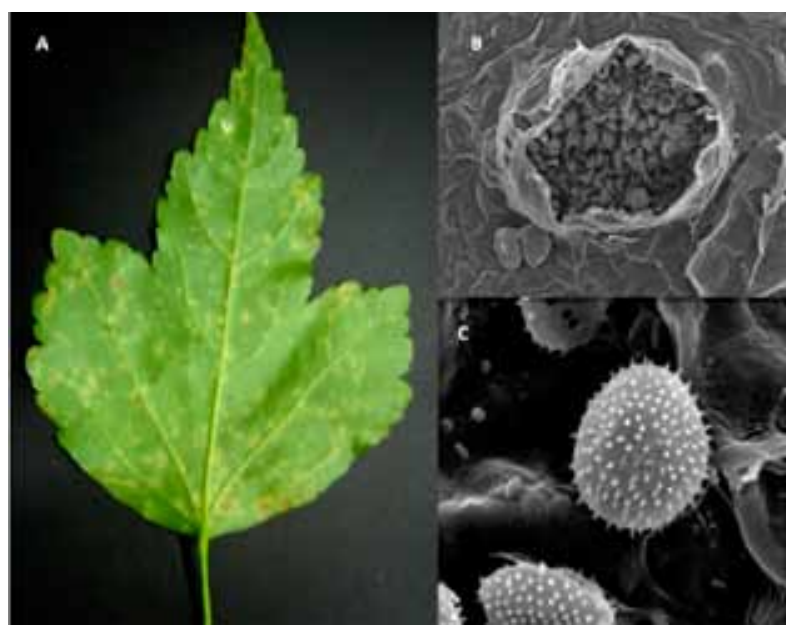

Fig. 2. A. Síntomas y signos de roya en rosa de Siria en reverso foliar. B. Pústula de Ceropsora en hoja de H. syriacus. C. Detalle de ornamentación y poros de las uredosporas (MEBx1800). 


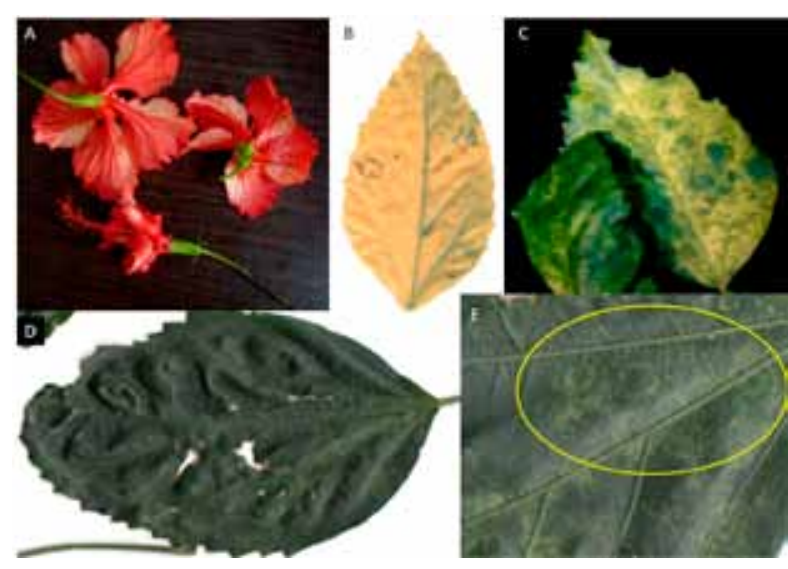

Fig. 3. A Síntomas virales en flores y hojas de $H$. rosa-sinensis (B, C, D). E. Detalle de anillos cloróticos.

de 10 géneros de malváceas. $P$. malvacearum produce pústulas muy oscuras y brillantes y teliosporas bicelulares características del género. Este patógeno fue observado en la región sobre otras especies de malváceas, no sobre rosa de Siria. Vemos que las características del género Puccinia no concuerdan con lo observado en el material en estudio. Por otro lado, Juan C. Lindquist (1982) informó además la existencia de Kuehneola malvicola Arth. sobre malváceas, no hallado en el país hasta el momento de su publicación. Este hongo produce uredosoros hipófilos, subepidérmicos, pequeños, pulverulentos, moreno canela, esparcidos o aglomerados, descubiertos, con paráfisis hialinas, cilíndricas y encorvadas, rodeando al soro; uredosporas obovoides, globosas y elipsoides de $15-20 \times 17-25 \mu \mathrm{m}$, membranas hialinas con espínulas ralas y poros germinativos situados en el ecuador, poco visibles. Teleutosoros hipófilos con teleutosporas multicelulares, de membranas hialinas, lisas de pedicelo corto, sobre numerosas malváceas, incluso Hibiscus pero que en Argentina no había sido encontrado sobre este hospedante. A su vez Cummings (1996) describe al género Kuehneola separado de Catenulopsora Mundkur \& Thirumalachar (1945). Como resultados de los estudios realizados se observa que las características morfométricas del patógeno observado en $H$. syriacus se ajustan en parte a las descripciones ofrecidas por Lindquist y Cummins para Catenulopsora (=Kuehneola), aunque algunas diferencias nos llamaron la atención, como la presencia de algunas esporas trilobadas compuestas por esporas compactadas. Cuando se liberan las esporas mantienen un ligero achatamiento dorsiventral. La célula basal hialina y ligeramente alargada impresiona como pedicelo. Esto fue lo observado en el material de Corrientes. Por otro lado Buriticá y Pardo-Cardona (1995), mencionaron a Catenulopsora praelonga (Speg.) Buriticá (=Rostrupia praelonga Speg., 1896), sobre especies colombianas de la familia Malvaceae El mismo Lindquist (1982) informó que el hongo fue observado por Spegazzini en Sierra de la Ventana (Argentina) en 1896 sobre Pavonia glechomoides A. Juss. como Kuehneola malvicola (Speg.) Arthur $(1912)=$ Cerotelium malvicolum (Speg.) Dietel (1928). El anamorfo es Macabuna malvicola (Speg.) Buriticá (1995). En la identificación de este patógeno se lo determinó como Catenulopsora praelonga (Speg.) $\mathrm{Bu}-$ riticá, = Cerotelium $\mathrm{sp} .=$ Cerospsora $\mathrm{sp}$. de acuerdo a Cummins \& Hiratsuka (1996), hongo perteneciente a la familia Chaconiaceae Cum. \& Y. Hirata (1996).

\section{VIROSIS}

En las plantas de Sinencia también se observaron órganos foliares y flores que se reducían de tamaño y se distorsionaban (Fig. 3A). En estas plantas las hojas manifestaban puntuaciones amarillas muy abundantes, distribuidas alrededor o próximas a las nervaduras principales de las hojas más jóvenes. Junto a estos síntomas no se detectaron signos visibles. En otras plantas o a veces simultáneamente en las mismas plantas las hojas que alcanzan mayor tamaño desarrollan anillos tanto cloróticos como necróticos o los llamados "diseños en líneas", sintomatología exclusiva de algunas virosis (Agrios 2005) (Fig. 3 B-E).

Por estos síntomas se determinó que existe la presencia de un complejo virósico que está según nuestras observaciones, ampliamente distribuido en las plantas de rosa china por toda la ciudad de Corrientes. En plantas con infecciones de mayor tiempo, las hojas y flores presentan mosaicos y variegados en amarillo o blanco, distorsiones y reducción de tamaño. Los síntomas de esta virosis se observan también con frecuencia en especies de Malvaceae silvestres y en los ejemplares ornamentales de farolito japonés (Abutilon sp.), malva (Malva rubia), escoba dura o pichanilla (Sida rhombifiolia y Malvastrum coromandelianum). En ninguno de estos materiales fue posible observar signos de enfermedad. De acuerdo a lo descripto en las obras de Albuy y Devergne (2000) y Llacer et al. (2000) podría tratarse del Hibiscus (chlorotic) ringspot carmovirus (HCRSV) junto al Abutilon Mosaic Virus Morren (AMV) sobre ambos hospedantes.

\section{CONCLUSIONES}

En la provincia de Corrientes las especies de $\mathrm{Hi}$ biscus cultivadas como ornamentales son afectadas por hongos que producen diversos síntomas de enfermedad. Colletotrichum gloeosporioides causa antracnosis en $H$. rosa-sinensis y $H$. syriacus; un cercosporoide, Cercospora hibisci causa lesiones tipo viruela en $H$. rosa-sinensis. También se identificó una roya causada por una cepa de Cerospsora sp. en H. syriacus. Se observó asimismo, la infección de 
patógenos virales similares, sintomatológicamente, a Hibiscus chlorotic ringspot carmovirus (HCRSV), junto al Abutilon mosaic virus Morren (AMV) sobre ambos hospedantes.

\section{BIBLIOGRAFÍA}

Agriculture Handbook No 165. 1960. Index of Plant Diseases in the United States. Agricultural Researches Service. Washington.

Agrios G. 2005. Plant Pathology. Fifth Ed. Elsevier. Academic Press. New York. USA

Albuy J. \& Devergne JC. 2000. Enfermedades producidas por virus de las plantas ornamentales. Versión española JM Mateo Box. Ediciones Mundi-Prensa, Madrid, España.

Álvarez R. E. y Cabrera M.G. 2008. Etiología de manchas foliares en rosa de siria (Hibiscus syriacus), en Corrientes; Argentina. Reunión de Comunicaciones Científicas y Técnicas de la SGCyT, UNNE.

Arx J.A. von. 1970. The genera of fungi sporulating pure culture. Cramer, Lehre.

Barnett H.L. \& Hunter B.B. 1972. Illustrated Genera of Imperfect Fungi. Burgess Publishing Company. Minneapolis, Minnesota. USA

Braun U. \& VA. Melnik. 1997. Cercosporoid Fungi from Russia and Adjacent Countries. Russian Academy of Sciences. St. Petersburg. (si tomás la premisa de poner como Bartent $\&$ Hunter apellidos primero y luego nombres se debe respetar en todo el listado de bibliografía)

Buriticá P. \& Hennen J.F. 1994. Familia Phakopsoraceae (Uredinales). 1. Géneros anamórficos y teleomórficos. Revista de la Academia Colombiana de Ciencias. Vol. 19 (72): 48-62.

Buriticá C.P. \& Pardo-Cardona V.M. 1995. Flora Uredineana Colombiana. Revista de la Academia Colombiana de Ciencias. Vol. 20 (77):183-236.

Cabrera MG. y Gutiérrez SA. 2003. Presencia de roya en Hybiscus syriacus en cultivos de Corrientes, Argentina. Horticultura Argentina: Resúmenes XXVI Congreso Argentino de Horticultura. Vol. 20/ 22 - N 49/52 2001/2003. p. 63.
Cummins G.B. \& Hiratsuka Y. 1996. 3rd. imp. Illustrated Genera of Rust Fungi. Revised Edition. APS Press. St. Paul, MN USA: 81.

Dawghtrey M.L., R.L. Wick \& J.L. Peterson.1995. Compendium of Flowering Potted Plant Diseases. APS PRESS, St. Paul, MN, USA.

Ellis M.B. 1971. Dematiaceous Hyphomycetes. Commonwealth Mycological Institute. Key. Surrey. England.

Ellis M.B. 1976. More Dematiaceous Hyphomycetes. Commonwealth Mycological Institute. Key. Surrey. England.

Fernández Valiela M. V. 1979. Introducción a la Fitopatología. 3 ed. Buenos Aires, Colección Científica INTA. vol. IV. Hongos y Micoplasmas : 129 y 425468.

French, E.R \& T.T. Hebert. 1980. Métodos de investigación fitopatológica. San José, Costa Rica, Instituto Interamericano de Ciencias Agrícolas de la OEA.

Hawksworth DL; Kirk PM; Sutton BC \& Pegler DN. 2000. Ainsworth and Bisby's Dictionary of the Fungi.Int.Mycol.Inst. CAB International. Egham, Surrey, UK

Lindquist J.C. 1982. Royas de la República Argentina y Zonas Limítrofes. INTA, Colección Científica Tomo XX. Buenos Aires, Argentina.

Llácer G; López MM; Trapero A \& Bello A. Edits. 2000. Patología Vegetal. Phytoma-Soc.Esp.de Fitopatología y Mundi-Prensa. Barcelona, España. Tomo 1 Virología.

Planeta-De Agostini 1987. Plantas de interior, terraza y balcón. Edit. Planeta - De Agostini, Barcelona. v 25, $\mathrm{n}^{\circ}$ 1, Hibiscus., p 292.

Murdoch Books 2008. The A-Z Garden Plants. Random House Mondadori S.A. Barcelona, España.

Sosa de Castro N.T., Cabrera M.G. y Álvarez, R.E. 2002. Etiología de manchas foliares en rosa de la china ( $\mathrm{Hi}$ biscus rosa-sinensis). XIII Reunión de Comunicaciones Científicas y Técnicas de la Facultad de Ciencias Agrarias, UNNE.

Sutton B.C. 1980. The Coelomycetes. Fungi imperfecti with Pycnidia acervuli and Stromata. Commonwealth Mycological Institute, Kew, Surrey, England. 